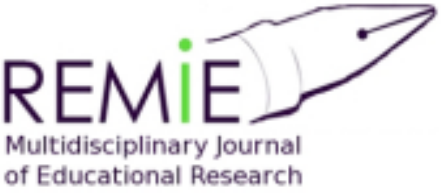

Multidisciplinary journal

of Educational Research

\section{Hipatia Press}

www.hipatiapress.com

Instructions for authors, subscriptions and further details:

http://remie.hipatiapress.com

\title{
Patrones de Movilización Cognitiva: Pautas para una Interacción Dialógica en el Aula.
}

Silvia Molina

1) Universidad Rovira i Virgili. España.

Date of publication: June $15^{\text {th }}, 2017$

Edition period: June 2017 - October 2017

To cite this article: Molina, S. (2017). Patrones de Movilización Cognitiva: Pautas para una Interacción Dialógica en el Aula [Review of the book]. REMIE-Multidisciplinary Journal of Educational Research, 7(2), 249-251. doi:10.17583/remie.2017.2758

To link this article: http://dx.doi.org/doi:10.17583/remie.2017.2758

\section{PLEASE SCROLL DOWN FOR ARTICLE}

The terms and conditions of use are related to the Open Journal System and to Creative Commons Attribution License (CC-BY). 
REMIE - Multidisciplinary Journal of Educational Research Vol.

7 No. 2 June 2017

\section{Review}

Mora, J., \& Aguilera, A. (2016). Patrones de Movilización cognitiva: Pautas para una interacción dialógica en el aula. Sevilla: Editorial de la Universidad de Sevilla. ISBN: 978-84-472-1842-4.

Las teorías e investigaciones que mejor explican actualmente cómo se da el aprendizaje en las aulas $-\mathrm{y}$ fuera de ellas- tienen como componentes esenciales la interacción y el diálogo entre múltiples agentes (Aubert, Flecha, García, Flecha \& Racionero, 2008; Mercer \& Littleton, 2007; Wells, 2001). Si aprendemos a través de la interacción y el diálogo, cuantas más sean las interacciones dialógicas, y cuantas más personas y más diversas participen de esas interacciones, mayores serán las oportunidades de aprendizaje. Esta realidad conforma lo que se ha llamado el "giro dialógico del aprendizaje" (Racionero \& Padrós, 2010) y es esencial tenerla en cuenta en cualquier planteamiento que pretenda mejorar el aprendizaje del alumnado.

Mora y Aguilera parten de esta premisa, y con su obra Patrones de Movilización cognitiva: Pautas para una interacción dialógica en el aula hacen una aportación para mejorar las condiciones en que esas interacciones tienen lugar. El monográfico parte de los resultados de investigaciones previas en relación a un programa de enriquecimiento cognitivo denominado "Comprender y Transformar", dirigido a alumnado con dificultades de aprendizaje. Según explican los autores, los resultados de sus investigaciones mostraban que los patrones de interacción eran el componente con un peso más importante en el programa. Estos patrones de interacción son lo que en el libro se presentan como "patrones de movilización cognitiva", formas de interacción que diferenciaban las aulas más eficientes de las menos eficientes. 
Aunque los autores sitúan el origen del libro en una investigación empírica enmarcada teóricamente, el libro Patrones de Movilización cognitiva: Pautas para una interacción dialógica en el aula tiene una intención eminentemente práctica. Sus destinatarios principales son el profesorado que quiere mejorar las interacciones de aprendizaje en sus aulas -tanto entre profesorado y alumnado como entre el alumnado-. El objetivo es ayudarles a comprender en qué consisten esto patrones de movilización cognitiva y a ayudarles a aplicarlos. De hecho, el libro supone la publicación de un programa de entrenamiento compuesto por lo que los propios autores denominan "guías de trabajo", destinadas a formar al profesorado en la aplicación de estos patrones de movilización cognitiva.

La estructura del libro la forma, en primer lugar, una introducción, que explica el origen del libro, su finalidad y cómo está pensado para ser usado, y a continuación, 21 capítulos, cada uno de ellos dedicado a uno de los patrones de movilización cognitiva. Estos 21 capítulos siguen la misma estructura para facilitar su uso por parte de las personas lectoras: en primer lugar, una definición y breve descripción del patrón de movilización cognitiva; en segundo lugar, una justificación de la importancia de ese patrón; en tercer lugar, algunas sugerencias para su aplicación; y, en cuarto lugar, algunos aspectos complementarios. Estas diferentes secciones finalizan con propuestas de actividades en grupo pensadas para que el profesorado en proceso de formación consolide su aprendizaje sobre lo expuesto.

En síntesis, Patrones de Movilización cognitiva: Pautas para una interacción dialógica en el aula supone una obra relevante en el contexto educativo actual, y es especialmente importante por su orientación transformadora. Partiendo de la importancia crucial de las interacciones en el aprendizaje y del papel esencial que tiene el profesorado en promover las interacciones que contribuyan de manera más efectiva al aprendizaje, Mora y Aguilera ofrecen con este libro una herramienta destinada a capacitar al profesorado para incorporar en su labor docente formas efectivas de interacción que promuevan el aprendizaje del alumnado, no sólo de aquéllos con más dificultades de aprendizaje, sino de todo el alumnado en conjunto. 
251 Molina - Patrones de Movilización Cognitiva [Book Review]

\section{References}

Aubert, A., Flecha, A., García, C., Flecha, R., \& Racionero, S.

(2008). Aprendizaje dialógico en la sociedad de la información.

Barcelona: Hipatia.

Mercer, N., \& Littleton, K. (2007). Dialogue and the Development of

Children's Thinking: a sociocultural approach. London: Routledge.

Racionero, S., \& Padrós, M. (2010). The Dialogic Turn in Educational

Psychology. Revista de Psicodidáctica, 15 (2), 143-162. Retrieved from

http://www.ehu.eus/ojs/index.php/psicodidactica/article/view/808/680

Wells, G. (2001). Indagación dialógica: hacia una teoría y una práctica socioculturales de la educación. Barcelona: Paidós.

Silvia Molina, MEDIS - Grupo de Investigación Consolidado Metodología de la Investigación Educativa con Impacto Social. Universidad Rovira i Virgili 